EXTENDED REFLECTION SURVEY OF THE SAN ANDREAS FAULT ZONE

T. V. McEvilly

University of California, Berkeley

Berkeley, California 94720

USGS CONTRACT NO. 14-08-0001-16804

Supported by the EARTHQUAKE HAZARDS REDUCTION PROGRAM

OPEN-FILE NO.81-388

U.S. Geological Survey

OPEN FILE REPORT

This report was prepared under contract to the U.S. Geological Survey and has not been reviewed for conformity with USGS editorial standards and stratigraphic nomenclature. Opinions and conclusions expressed herein do not necessarily represent those of the USGS. Any use of trade names is for descriptive purposes only and does not imply endorsement by the USGS. 
U.S. Geological Survey

Earthquake Hazard Reduction Program

345 Middlefield Road

Men1o Park, Ca1ifornia 94025

FINAL REPORT

CONTRACTOR: The Regents of the University of California

DATE OF CONTRACT: 01 Feb 1978

CONTRACT TERMINATION DATE: 31 December 1979

AMOUNT OF CONTRACT: $\$ 302617$

CONTRACT NO: 14-08-0001-16804

PRINCIPAL INVESTIGATOR: T.V. MCEvil1y

(415) $642-4494$

SHORT TITLE OF WORK: Extended Reflection Survey of the San Andreas Fault Zone

Sponsored by the

U.S. Geological Survey

No. 14-08-0001-16804

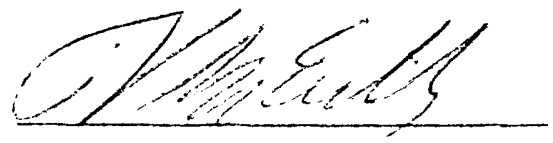

T.V. McEvil1y 
SAN ANDREAS FAULT ZONE, SAN BENITO COUNTY, CALIFORNIA

\section{T.V. McEvilly}

\section{TABLE OF CONTENTS}

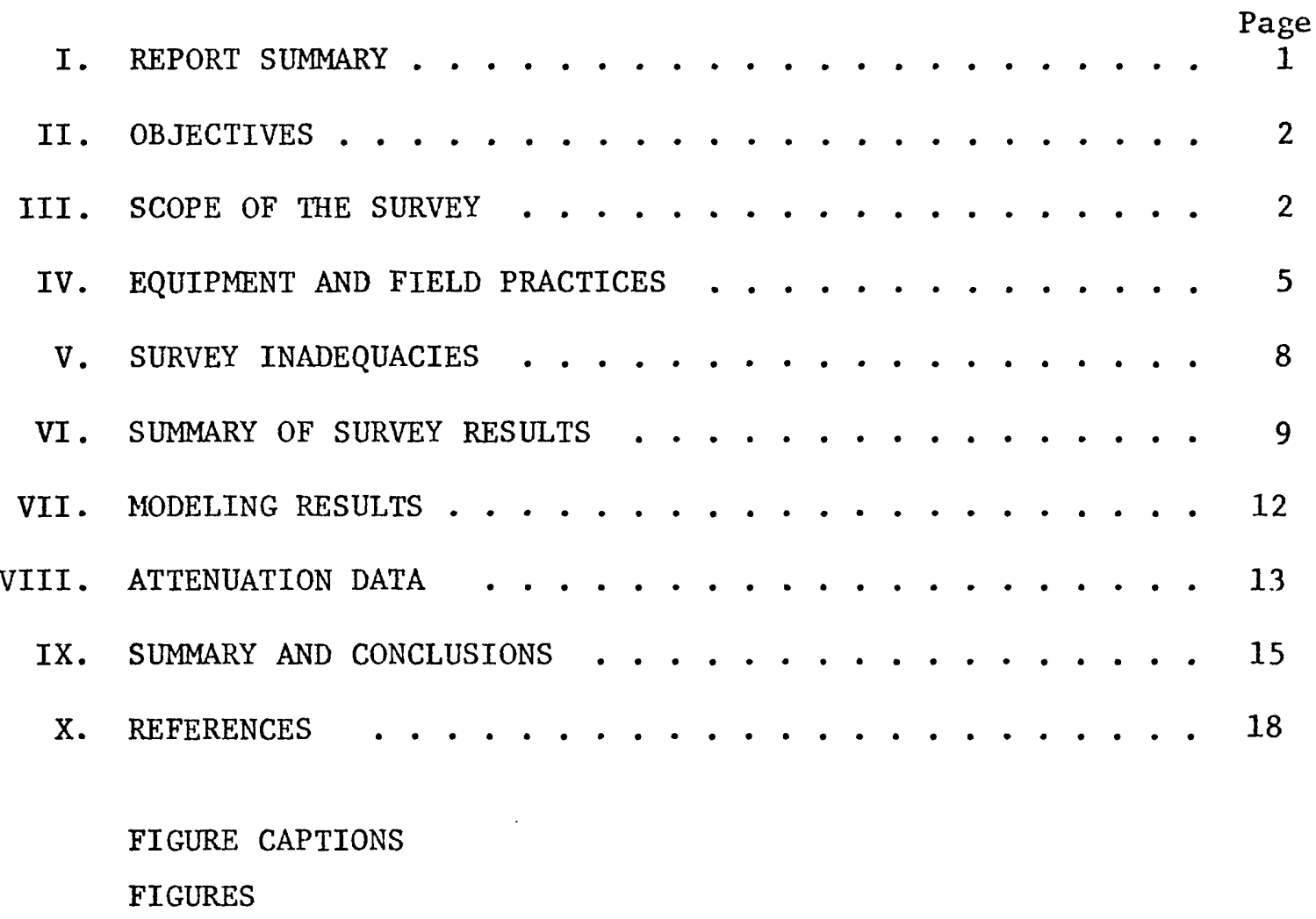


EXTENDED REFLECTION SURVEY OF THE

SAN ANDREAS FAULT ZONE, SAN BENITO COUNTY, CALIFORNIA

CONTRACT NO. 14-08-0001-16804

T.V. McEvi11y

Seismographic Station

Department of Geology and Geophysics

University of California

Berkeley, California 94720

(415) 642-4494

\section{REPORT SUMMARY}

An extensive reflection survey was conducted in 1978, crossing the San Andreas fault zone in San Benito County, California. Some $18 \mathrm{~km}$ of CDP coverage, up to 24 -fold, was obtained in addition to in-line and lateral offsets of up to $16 \mathrm{~km}$ and $8 \mathrm{~km}$, respectively, providing subsurface information of variable redundancy over a distance of $44 \mathrm{~km}$ along the profile (WSW-ENE) and in a $6 \mathrm{~km}$-wide strip along the profile at the fault zone. The full data set with maps and sections was presented in the first Technical Report for the contract and is not reproduced here.

The purpose of the survey was 1) to extend across the fault a previous survey line wholly west of the fault showing good deep data, 2) to obtain velocity information in the contrasting granitic and Franciscan crustal plates and possibly the fault zone, investigating the possibility of a low velocity wedge extending from the seismically active $(\sim 3-10 \mathrm{~km}$ depth) section of the fault zone several $\mathrm{km}$ laterally into the crustal blocks, 3) to provide sites for recording reflections with strategic paths in our program of travel-time monitoring, and 4) to provide preliminary information on the feasibility of a 3-dimensional seismic imaging for velocity and structure within the fault zone.

Data in the granitic crust show generally good reflections to the base of the crust, seen as a series of arrivals over nearly $10 \mathrm{~km}$ of transition. Along the entire CDP line there are apparent reflections to $3.0 \mathrm{sec}$ travel-time, but within the Franciscan crustal block there appears to be a diffusion of energy as if by back scattering and attenuation, with very little return from the lower crust, in marked contrast to the granitic section to the west. The fault zone is characterized by high attenuation, some shallow coherent arrivals, and several apparent diffractions. The interval 4-6 sec appears generally non-reflective, possibly related to the depth $(10 \mathrm{~km}+)$ of the onset of stable sliding in the fault zone.

Extensive lateral velocity gradients are seen, with a decrease of some $30 \%$ over about $5 \mathrm{~km}$ approaching the fault zone from the granitic side. Such gradients make difficult the tasks of stacking properly the multifold data and preclude the use of flat-layer algorithms for velocity estimation. This problem has been addressed during the no-cost extension period of the contract. Forward ray-tracing modeling of first arrivals and reflections provides a velocity distribution which satisfies the data under some constraints. The resulting model features a very low velocity fault zone and a strong lateral velocity gradient within the western fault block with a probable low-velocity wedge extending at least $5 \mathrm{~km}$ laterally from the fault zone in the depth range of $3-8 \mathrm{~km}$, coinciding roughly with that of the seismicity. 


\section{OBJECTIVES}

This survey had four main objectives:

1. To extend the structural information from a previous survey into and beyond (to the east) the San Andreas Rift Zone.

2. To obtain velocity information for both the Gabilan granite area and the Franciscan area which would be both more extensive geographically and more accurate. It was hoped, although this was a much more difficult assignment, to obtain some knowledge of the velocities within the Rift Zone itself.

3. To provide information on good reflecting areas which would allow establishment of permanent sites, near the Rift Zone, for monitoring of temporal changes in velocity.

4. To provide preliminary information on the problems and possible solutions for the investigation of three-dimensional structure and velocities in the vicinity of the San Andreas.

\section{SCOPE OF THE SURVEY}

This work was aimed at obtaining reflection and refraction data from which deep crustal geological information could be inferred. In order to accomplish this objective, the survey had to include seismic sources and recelvers located in both San Benito and Monterey Counties, California. The general layout is shown in Figure 1. It will be noted that the survey centers on Bear Valley and the area is approximately bisected by the San Andreas Rift Zone.

Previous Common Depth Point (CDP) reflection seismic work has been done under U.S.G.S. Contract No. 14-08-0001-14845, but was restricted to two CDP lines, namely:

1. A part of the La Gloria Road which lies in Bickmore Canyon (southwest quarter of the U.S.G.S. 15 minute topographic sheet, San Benito quadrangle) and,

2. Along the Panoche Road paralleling Tres Pinos Creek (northwest quarter of San Benito 15 minute quadrangle).

The geographic 1imits of the surveys are shown in Figure 1 . The line occupled by the geophones lies entirely within San Benito County and consists of the part which is on La Gloria Road, in Bickmore Canyon, a part which crosses open country in Bear Valley and descends to cross the San Benito River valley and from there the line proceeds generally east by a private road and trail, past Bald Mountain to the headwaters of Salt Creek. Near the Lower Butts Ranch (Section 5, T16s-R8E) there is a 500 foot high cliff to be negotiated, necessitating a cable pullout and the loss of one vibrator source location as well as a geophone array. 
However, the subsurface coverage is not limited to the geophone line itself, but has been expanded by the use of some longitudinally offset vibration points. These are shown on Figure 1 by points designated $L-(x)$. In addition, some laterally offset points (designated $\mathrm{N}-(\mathrm{x})$ ) were used. Their function will be described later.

By the use of the longitudinally offset points $\mathrm{L}-0$ through $\mathrm{L}-4$, the subsurface coverage was extended beyond the CDP line to the west. This information was not redundant as was the $\mathrm{CDP}$ data, so that only approximate inferences can be drawn. In a similar manner, the geophone spread from VP 200 to VP 247 was recorded using eastern longitudinally offset vibrator points by $\mathrm{L}-7$ through $\mathrm{L}-10$.

The field survey itself was divided into two recording periods in early 1978, due to inclement weather and a permit problem aggravated by soft ground. During the early part of the first period (April 3-28) the vibrator points L-0 to L-4 were recorded using the geophone spread 200-247. Later in this period, vibrator points 200-259 were used, the recording spread advancing ahead of the vibrators, leaving a five interval gap between vibrators and the first geophone group. When the vibrators had reached VP 259, the county officials responsible for San Benito County roads withdrew previously given permission to vibrate on non-paved county roads. While a small amount of damage had been done to the road surface of La Glorla Road, this was subsequently repaired by the county and was not the princlpal reason for the withdrawal of the permit. Rather, it was due to pressure exerted by one or more ranchers who were, unfortunately, inconvenienced in their use of the La Gloria Road for haulage of cattle in the annual Spring relocation.

The crew was then laid off for a period until the Spring rains had stopped and the cross country part of the reflection line (from VP 273 to VP 357) was traversable. The second period started on June 3 and finished June 15. During the second period, the lush grass and vegetation dried up under the summer sun and created a fire hazard which both delayed and, in one case, limited the survey coverage.

Due to the permit problems and other problems caused by terrain and fire hazards, the full 24-fold coverage was not always possible. However, after the return to the field following the hiatus due to permits and weather, an approach was adopted to use some geophone groups to the west of the vibrators and some to the east. Forty-eight groups were always recorded, but the maximum offsets were not as long and redundancy was achieved by using both east and west short offsets as well as longer east offsets.

Following the recording hiatus, the crew found on its return that the first VP which could be occupled was VP 273 and, had the geophones continued to be laid only in a forward direction, there would have been a considerable drop in redundancy from VP 275. However, by laying and recording geophones backwards to VP 249 and forwards to VP 305, an acceptable stacking capability was possible. This arrangement of 20 traces back and 28 forward (with a 10 interval gap between and the vibrators in the center of the gap) was maintained up to VP 325. From VP 326 onwards, the vibrators moved through the existing spread laid out to VP 357 in order to complete the line.

The entire line can be imagined as consisting of three segments: 


$\begin{array}{ll}\text { Segment A } & \text { VP } 200 \text { to VP } 247 \\ \text { Segment B } & \text { VP } 262 \text { to VP } 309 \\ \text { Segment C } & \text { VP } 305 \text { to VP } 352\end{array}$

In each of these positions for the CDP spread, the cable movement was temporarily halted in order to perform other experiments using either L vibrator points or $\mathrm{N}$ - vibrator points.

For Segment A, these auxiliary experiments were unhampered by permits and limited only by either the quality of the received seismic signal or by The quality of radio communication from the recording truck to the vibrators. A radio relay system had been provided, but in some areas steep local topography interfered with the needed line of sight transmissions, and the survey was stopped due to the poor fraction of readable triggering signals recelved. Four vibrator locations were recorded to the west of Segment $A$, at intervals of 4 miles $(6.4 \mathrm{~km})$, three at positions almost colinear with the line joining the ends of Section $A$, and the remaining one offset somewhat to the north. From these vibrator points (see Figure 1 ), designated $\mathrm{L}-1, \mathrm{~L}-2, \mathrm{~L}-3$, and $\mathrm{L}-4$, a series of offset records was obtained. Subsurface paths - for the refracted "events" - spanned the entire distance from VP to the geophone spread, but no information was available or could be accurately inferred for weathering corrections at the isolated VP's. The maximum offset ( $\mathrm{L}-0$ to $\mathrm{L}-4$ ) was about 16 miles $(25.6 \mathrm{~km})$. For reflections, these isolated VP's provided subsurface information over one half of this distance. Originally, these western offsets were intended to extend beyond the Sierra de Salinas Mountains, but both radio and ground transmissions became too weak.

Simflar long offset work was done with the geophone spread in Segment A, using vibrator points $\mathrm{L}-7, \mathrm{~L}-8, \mathrm{~L}-9$, and $\mathrm{L}-10$. In this case, the refracted and long offset reflected events would have to pass through the San Andreas Rift Zone in order to be recorded. L-10 (at a distance of 12 miles from the near end of Section $A$ ) was found to be at the practical limit of offset recording in the eastern direction.

With the recording spread in Segment $B$, the longitudinal offset points $\mathrm{L}-8, \mathrm{~L}-9$, and $\mathrm{L}-10$ were used. In this case, the geophone spread was almost bisected by the San Andreas Rift Zone.

A second type of recording, with the cable in Segment B, was to make use of vibrator locations several kilometers laterally offset from the line. The VP's used in this manner were $\mathrm{N}-2 \mathrm{~A}, \mathrm{~N}-3, \mathrm{~N}-12, \mathrm{~N}-13, \mathrm{~N}-14$, and $\mathrm{N}-16$. Any coherent energy from such VP's would then, after appropriate near surface corrections, give a cross section across the San Andreas Rift Zone, with energy picked up (on one side or the other) which would have had to travel through the fault zone. In order to avoid the problems of possible near surface travelling waves, the recording geophone arrays had to be aligned with the line joining the spread to the VP concerned. It is obvious that to do this accurately for each lateral offset VP would have resulted in considerable delays. Fortunately, it was found sufficient to lay the individual arrays at right angles to the local spread. Deviations from optimum usage were belleved to be small, since the effectiveness of the arrays was nearly proportional to the cosine of the angle between the source-receiver line and the axis of the geophone array. 
A few additional laterally and longitudinally offset points were obtalned with the spread in Segment $C$. Time, permits, and inaccessible terrain prevented the crew from recording all that were desired.

Some additional information was acquired by serendipity. Three small earthquakes occurred during the time that the crew was actually recording. Since we had anticipated that this could happen, provisions were made to retain these records and to re-record the same vibrator-geophone spread traces for reflections. Two of these earthquakes were identified by time of occurrence and their calculated locations have been made avallable to the U.S. Geological Survey.

In all, the reflection survey provided the possibility of obtaining subsurface reflection information over a distance of approximately 27.2 miles $(43.8 \mathrm{~km})$ in an east-west direction and about $4.3(5.8 \mathrm{~km})$ north-south along the rift zone.

\section{EQUIPMENT AND FIELD PRACTICES}

Previous experience had suggested that every method of improving signal to noise ratio should be taken. The improvement can be brought about by:

1. Using the optimum sweep of frequencies so as to exclude those which play a less important role in obtaining reflections. Due to the expected high attenuation of the reflected signals and the proportionality of the attenuation coefficient to frequency, low frequencies should be emphasized. Scattering of seismic waves also increases at the higher frequencies. On the low frequency end of the spectrum, the energy input is limited by vibrator features. In the case of the Mertz "heavy" vibrators, the lower limit is $6.0 \mathrm{~Hz}$ caused by limited stroke and limited mass of the vibrator reaction mass.

For these reasons, the sweep frequency band was chosen to be the two octaves $24-6 \mathrm{~Hz}$.

2. The sweep length of a linear sweep also plays an important role, since energy is transmitted to the ground during the entire sweep period. This, and another consideration, that of "ghost elimination," means that the swept frequency signal should be as long as possible. The generation of low frequencies by present day vibrators, because of the non-linear behavior of the earth, is accompanied by the simultaneous generation of harmonics. These harmonics, after travelling through the earth and being reflected like their fundamental, in the later correlation process, correlate with their real frequency counterparts in the swept frequency control signal. Such "spurious" correlations are "ghosts" of each reflected, refracted, and surface wave and they occur at a delay time which is controlled by the generation delay between the fundamental and the particular harmonic. Thus, since we have 
chosen $6 \mathrm{~Hz}$ at the lowest frequency of the swept frequency signal, its harmonic will correlate with the natural occurrence of $12 \mathrm{~Hz}$ in the control signal. If the control signal were 36 seconds long, the instantaneous frequency would increase by $\frac{24}{36}-6$ or $0.5 \mathrm{~Hz}$ every second, and the "ghost" would follow the real seismic event by 12.0 seconds.

In this survey, the maximum duration of the sweep signal is limited by both the sweep generators and by the storage capacity of the instrumentation memory. An effective limit to sweep length is reached at 32 seconds. The theoretical "ghost" time is thus $6 \times 32 / 18=10.67$ seconds. However, a taper for 0.5 seconds is imposed on the sweep (to prevent ringing at each sharp cut-off at the beginning and end of the sweep). This raises the effective lower limit of the sweep to about $6.2 \mathrm{~Hz}$ and the "ghost time" is now likely to be about 11 seconds.

The use of an "up sweep" is sometimes recommended. This would have the effect of putting the "ghost signal" ahead of zero time on the correlated record. However, other difficulties of vibrator phase compensation then arise and, with unknown phase compensation systems, it is better to play safe, use the "down sweep" and realize where it is likely to cause problems as far as the correlated record is concerned. In this survey, the "ghosts" were in little evidence, although a few first arrival "ghosts" did occur and these will be pointed out 1ater.

3. Obviously, the number of sweeps or the total time of vibrating enters into the amount of energy transmitted. This number is a compromise among a number of other factors. The vibrator array will be chosen, later, in order to diminish the amplitude of near surface waves recorded. Obviously, the number of positions in the array must be large enough to give a fine enough sampling interval so that aliasing is avoided. Note that this can be a requirement affecting the rapidity of the survey. A surface wave of $24 \mathrm{~Hz}$ may be travelling at a phase velocity of $1000 \mathrm{ft} / \mathrm{sec}$ and thus have a wavelength of $42 \mathrm{ft}$, which should be sampled at least four times per wavelength. In this survey, this would have inordinately decreased the speed of coverage since 66 vibrator positions would have been required. In practice, this requirement is mitigated to some extent by the fact that 3 or more vibrators were used and these follow each other at distances of about $10 \mathrm{ft} / \mathrm{head}$ to tail. The move up distances are not multiples of this distance between vibrator baseplates, so that the ground coverage is sampled, on the average, better than required. Another factor in the avoidance of aliasing of surface waves is that the geophone interval is not the same as the vibrator interval. The convolution of the source array transfer function with the transfer function of the geophone array causes the sampling also to be composited (see Muir and Morrison (1973)). 
The compromise used for the number of sweeps per vibrator array was 32 . It is possible, when using an Add-It or simflar device which adds trace energy during recording, to use a larger number of sweeps, but this was only done when absolutely necessary - as, for example, for very large offsets. In the equipment being used, the Ilmit which can be used was 99 sweeps. In some cases, this number (pre-set into the equipment) was used. Another consideration later changed the tactics. Since this area was a seismically active one, with numerous small earthquakes along the San Andreas Rift Zone, the chance of interruption of a reflection recording sequence was reasonably high. The earthquakes vere sometimes large enough ( $M<5.0$ but usually $0.5<M<2.5$ ) to swamp the energy provided by vibrators. This, of course, was occasionally desirable since the ensuing impulsive recording could provide excellent information. Too many, however, would have prevented the VIBROSEIS reflection survey altogether.

Therefore, for points which required large injection times, the later practice was to record for a pre-set 33 or more sweeps and follow this by additional independent groups of 33 , the resulting records being added together in data processing.

It was decided to adopt a sampling interval of 0.008 seconds for all data. Note that this provides 5 points per cycle for the highest frequency of interest $(24 \mathrm{~Hz})$. An analog antialias low pass filter cutting off at $31.25 \mathrm{~Hz}$ at a rate of $48 \mathrm{db} /$ octave provided assurance that little energy was recorded above this frequency. For a sample rate of 0.008 seconds, the Nyquist frequency is $62.5 \mathrm{~Hz}$. The chief reason for using 0.008 seconds instead of the more usual 0.004 seconds was to accommodate the longer sweeps and recording time. In a11, the memory capacity was sufficient to store 48 seconds of data for 48 channels at a sampling rate of 125 samples/second. Using a sweep length of 32 seconds, there would be adequate storage for an additional recording of 16 seconds "1istening time" (past the "ghost" arrival time and well past the expected reflection arrival times). An entire source array could be occupied in well under one hour, thus allowing 8-13 vibrator points to be occupled in one day.

4. The number of vibrators is a critical factor, as is the peak force which can be applied by each vibrator. For this survey, the largest generally commercially available vibrators were specified. Four were available to be used whenever possible. However, recording could proceed with three in an emergency but recording was to be discontinued when less than three were available. Vibrator similarities were taken at least once a day. The difference between 4 and 3 vibrators can only be made up by vibrating (under conditions of Gaussian noise distribution) for $(4 / 3)^{2}=1.78$ times as 1ong. This is obvious1y a large factor and the drop to 2 vibrators, meaning a loss of signal to noise of $12 \mathrm{db}$, could not be accommodated. 
The array was set at $880 \mathrm{ft}$ total length and consisted of 36 geophones ( 4 groups of 9) recorded as a single trace. Geophones were $8 \mathrm{~Hz}$ natural frequency and, when used with critical damping, had an output down by $3 \mathrm{db}$ from maximum. There was little loss in amplitude, therefore, at $6 \mathrm{~Hz}-$ certainly insufficient to counter the advantage of robustness which $8 \mathrm{~Hz}$ geophones have over the $4 \mathrm{~Hz}$ geophones used previously. Sufficient geophone "strings" and cable sub-elements were provided to allow the geophone spread to be lald out well ahead of the portion being recorded. All geophones were buried to lessen wind noise and airborne vibrator noise. The latter was troublesome in a few locations.

The combination of an $880 \mathrm{ft}(268 \mathrm{~m})$ geophone array with 36 geophones and a source array of $660 \mathrm{ft}(201 \mathrm{~m})$ with 32 source positions, gave rise to a highly directed system response. In fact, the practical directivity is probably even higher due to the near cosine dependence of output of the vibrator and the same acceptance factor for the geophones as a function of the angle between the ray path and vertical. It will be later noticed that some of the reflections have an angle of emergence near $20^{\circ}$, but this is well within the high acceptance region of the combined array directivity. A problem does exist when using such long arrays in difficult mountainous terrain due to possible reflection energy cancellation by phase difference due to elevation differences of geophones within the same group. For the highest frequencies used here, the elevation corrections would have had to be greater than .020 secs (one half period) and, for a large part of the survey area, this would have corresponded to $160 \mathrm{feet}$. The observer was instructed to shorten the group coverage under such circumstances.

\section{SURVEY INADEQUACIES}

With the advantage of the hindsight offered by a year's additional data manipulation, it is now clear that three substantial shortcomings existed in the field survey as conducted. While these were fundamentally errors on the part of the contractor, CGG, we should have been more insistent in our supervision of the field crew. In all faimess to CGG, this type of survey was quite different from a conventional petroleum exploration effort, and the special vulnerability of deep sounding results to lost signals was poorly appreciated. The three problem areas were:

1. Poor Radio Communication. This item rendered the long offset experiments virtually impossible beyond about 15 miles. In the survey specifications, we listed as required the capability, via relays or any suitable link, to control the vibrators to distances as far as the coast, some 30-40 miles. In fact, the supplied system was so poor that most sweeps were being lost (the vibrator was not receiving the start code) at 20 miles, forcing cancellation of the longer offset tests and severely degrading signals at the shorter offsets due to lost sweeps. In retrospect, the proper action would have been to demand a functioning link - in the field it was not clear that communication was the entire problem. 
2. Instrumental Noise. On early processed records we noticed a distinctive and systematic noise pattern throughout the data, a pattern best explained by digital noise (spikes and steps) on the uncorrelated records. This analysis was presented to the field crew management, who, after some consideration, rejected it. Only many months later, at Geodigit in Denver, were we able to obtain conclusive proof that, yes, in fact, the raw uncorrelated data in many cases were severely contaminated by just such systematic noise. The noise is probably introduced in the field summing system (ADIT), and is apparently a problem with the lower order bits. Unfortunately, at the long offsets and long records of this survey, most of our desired data reside in the lower order bits. In retrospect, it would have taken real guts to shut the crew down when their experts denied a problem, but it should have been done.

3. Inoperative Vibrators. Well into the survey, it became apparent that only three vibrators were operating most of the time. Upon questioning, CGG admitted to a policy of keeping one unit out of service for maintenance on a more-or-less continuous basis, claiming that the specification "... 4 vibrators, minimum of 3 operating..." allowed such procedure. In this case, we were successful in changing procedures, and 4 operating units became the norm.

I an convinced that these three problems, particularly the latter two, contributed substantially to the fact that the data acquired were less than optimum in quality, as evident in the final sections. Looking back, it appears certain that the problems were all a result of the crew scheduling policies of CGG, which provided for no days off - i.e., the crew would work continuously on a job, even of 3-4 weeks duration or more, accumulating days off for between jobs. This produced a terrible crush of maintenance and repairs scheduling, not to mention the reduced capabilities of workers on a continuous schedule and the lack of time for consideration and resolution of problems such as 1 and 2 above. We have made it clear to CGG that we would not contract their services again under such operating policies. Signals are so small in deep reflection surveys such as this that a factor of even two in degradation can spel1 the difference between success and failure. It is imperative that the contractor be cognizant of this fact, and that every step is taken to assure the maximum signal-to-noise ratio.

\section{SUMMARY OF SURVEY RESULTS}

The extensive Common Depth Point reflection survey crossing the San Andreas Rift Zone in the vicinity of Bear Valley was supplemented by recordings taken with source locations as far as $16 \mathrm{~km}$ to the west and $12 \mathrm{~km}$ to the east of the recording spread of geophones.

Six laterally offset sources provided some data which aided in assessment of the three-dimensional continuity of the structure found. By luck, two small earthquakes were recorded and provided valuable velocity information. The second of these, near the Melendy Ranch, was fortunately in such a position 
that a nodal line in the radiation pattern (at right angles to the slip direction) intersected the recording spread and provided additional, detailed information on lateral velocity variation.

A strong gradient of average velocity away from the fault zone has been found. A velocity change of $29 \%$ within approximately $5 \mathrm{~km}$ of the fault had been suspected, but has now been proved. Farther to the west the gradient becomes more gentle and may reverse itself as the line encroaches on the Salinas Valley. Due to the fact that these isolated shotpoints in the Salinas Valley gave rise to unreversed reflection or refraction profiles, it is not possible to separate the effects of dip of the reflectors and velocity change. Apparent dip, however, on the west end of the line (near L-1) appears to be to the west, giving rise to the speculation that further faulting may be present on the west side of the Salinas Valley causing velocities to be diminished.

The quality of the raw reflection records is best near VP 200, the west end of the CDP line, but a subsidiary area of good quality reflections has been found very near to the Rift Zone and a small amount near the east end of the line. These localities will be of considerable use in possible future temporal monitoring of reflection velocities. The stacked records are not as good in some of these areas due to the uncertainty of NMO corrections on most of the traces used for composite and the deterioration occurs due to interference of incorrectly adjusted raw records.

Elevation corrections were initially applied using a velocity of $8000 \mathrm{ft} / \mathrm{s}$ to correct to a flat datum. Subsequently, the individual records were subjected to the proprietary program AUTOSTATICS which did, in fact, within the allowance imposed of $50 \mathrm{~ms}$, make additional shifts which allowed a best fit of surface-consistent corrections with the raw reflection data.

Crooked line processing of the data involves correction for the straight line distances between relevant sources and receivers before NMO correction and, later, the ability to plot in three dimensions the raw data reflecting points. This is only a first approximation, since such a plot is based on the assumption of flat reflecting planes. Later it is possible to select bands of data for playout and also make estimates of the amount and direction of cross dip. This survey, using the proprietary SLALOM processing, showed appreciable cross-dip to the north. On the western end of the line this amounts to about $90 \mathrm{~m}$ in a distance of $244 \mathrm{~m}$ or an angle of $20^{\circ}$. This may, in fact, be the predominant real dip, since much of the apparent east dip shown on this western part of the CDP section is due to decrease in average velocity to the $M$ discontinuity toward the Rift Zone. The velocity effect is not present when comparing two cross-sections for two different SLALOM bands. The "Scattergram" therefore gives an incorrect relation between the VP's and the reflecting points, since the latter must be migrated to the south as a consequence of the north dip.

On the eastern side of the San Andreas Rift Zone, there is seen to be no cross component of dip measurable. There were, however, no determinations possible at Moho depth. 
Along the entire CDP line, reflections shallower than 3.0 seconds travel time can often be plcked with confidence. These reflections are so good in certain locations that abrupt change of quality must be due to faulting or to lateral discontinuity in the underside of the Gabilan granitic section, which may imply a change in crustal composition at about $8 \mathrm{~km}$ depth. There is also reasonable evidence of a lack of reflections generally in the 4.0 to 6.0 second travel-time zone, thus implying a travel medium in which the velocity changes only slowly. This is consistent with the low velocity zone previously suggested as being present and may explain, because of the presumption of low strength, the non-occurrence of earthquakes below about $10 \mathrm{~km}$. This is the zone where all stress adjustments are made easily and continuously, without seismic wave emissions accompanying fractures.

Below the 6.0 second travel-time depth, there is no evidence of disconformities in reflections, although their quality is poor. The reflections associated with the "M discontinuity" seem, in fact, to occur through a transition zone $10 \mathrm{~km}$ or more thick, although part of this apparent thickness is probably due to persistence of multiple reflections. To give reflections in the 6-24 $\mathrm{Hz}$ band, sudden changes in acoustic impedance must occur for zones from $125 \mathrm{~m}$ to $0.5 \mathrm{~km}$ thick or 1 ess.

The lateral offset source points gave rise to poor reflection records except that the apparent east dip to the west of the San Andreas was confirmed along lines associated with $\mathrm{N}-3, \mathrm{~N}-13$, and $\mathrm{N}-14$. Almost flat dip to the east of the San Andreas was shown by $\mathrm{N}-3$. It is presumed that the paths of reflections in planes almost parallel to the Rift Zone may have offered several alternative paths which could interfere, thus giving rise to virtually "unpickable" records. There is, on most of them, no lack of energy and hence increasing the number of sweeps would have resulted in little improvement.

Record sections, maps, and other data leading to the above interpretation have been submitted with Technical Report No. 1 on this research, and are not reproduced in this Final Report. Rather, we summarize here the data discussed previously, providing more detall on those aspects of the data analysis which have been addressed in the final months of the contract period.

While several technical papers on this and the previous survey have been presented at scientific meetings, the comprehensive journal article is as yet not completed. A degree of embarrassment is associated with this fact, particularly since much is being made these days of deep reflection surveys and their results as reported by the COCORP participants. A comprehensive treatment of both data sets on the San Andreas fault zone surveys is being completed at this time, and it should be in press by the year's end. 


\section{MODELING RESULTS}

A two-dimensional forward ray-tracing algorithm LATVH has been adapted for use in modeling the seismic velocity structure of the survey area. In this algorithm, a lateral velocity inhomogeneity model has been constructed, rather than the conventional uniformly layered structure, because of the strong evidence for such a situation near the San Andreas fault zone. Reflected ray paths can be traced (in this study we stress the M-discontinuity) as well as first arrivals, obtained by manipulating the takeoff angles of the forward propagating rays.

A starting model was based on the velocities given in the 1978 Technical Report. In that model, a low-velocity zone extends from the fault zone outward on both sides of the fault, in the depth range $3-8 \mathrm{~km}$. The crustal velocity of the east side is significantly less than that of the west side. By trial and error at the UC Berkeley CDC 6400 computer, the velocity model was modified to match the calculated time of first arrivals and reflections and those observed on the seismograms.

There are some constraints applied in this simulation:

1. The M-discontinuity is considered to be flat on both sides of the fault. This seems a reasonable first step, and relegates the extreme apparent dip to velocity effects.

2. Topography had not been taken into consideration. The elevation corrections would be second-order effects.

3. The algorithm is for two-dimensional modeling only, and this presents difficulties in modeling the seismic sections which were obtained from a crooked geophone spread crossing the fault zone somewhat obliquely.

The resulting velocity distribution, shown in Figure 2, features a very low velocity fault zone and a strong lateral velocity gradient within the western fault block with a probable low-velocity wedge extending at least $5 \mathrm{~km}$ laterally from the fault zone in the depth range of $3-8 \mathrm{~km}$. Figure 3 illustrates the distorting effect of such structure on ray paths for Moho reflections, while Figure 4 shows the effect on P-waves from an earthquake source on the San Andreas fault. Calculated first arrivals and reflections have been plotted on Figures 5 and 6 , the stacked and western offset seismic sections.

Since the ray tracing is two-dimensional, the crooked shot lines are difficult to simulate. A base line connecting L-10, L-9, L-0, L-1, and L-2 has been selected for this study. Shot point L-8 is offset to the south of the base line and requires a different velocity model. Figure 7 shows calculated first arrival and Moho reflection times for the eastern offsets. Shot points $\mathrm{L}-3$ and $\mathrm{L}-4$ are out of the modeling range, so their sections were not considered. In Figure 8, a true amplitude stacked section, equivalent to Figure 5, is presented. 
For further study, it is necessary to extend the two-dimensional modeling to three-dimensional simulation, which not only can fully utilize the data obtained in the last two surveys, but also provide the prerequisite geometry migration, which is an inevitable step in understanding the fine structure of the fault zone. The cost for the needed migration before stack on these data sets is too great to allow experiment with changes in the velocity model after it has been submitted to the processing center. Such a migration will be performed once a 'final' version of the velocity model is selected.

\section{ATTENUATION DATA}

A glance at the true amplitude stacked section in Figure 8 reveals an obvious transition from clear crustal reflections west of the fault zone, degrading eastward through the fault zone to a situation of little deep energy return east of the fault. The contrast between the granitic and Franciscan crustal reflectivity and that of the fault zone proper enables us to proceed with an estination of the attenuation and diffusivity differences between crusts of the North American and Pacific plates.

The absence of a clear Moho reflection or of reflections shallower than 3.0 seconds travel time in the fault zone and in the Franciscan crust suggests that incident energy is not being recovered coherently, i.e., as vertically propagating wavefronts. This situation can be interpreted as being due to a combination of elastic scattering and anelastic loss. Inhomogeneities within the Franciscan crust and the fault zone may provide the necessary impedance contrasts to yicld substantial scattering of seismic energy. Energy propagation in such regions can be modeled as a diffusion process.

The diffusion equation including dissipation is:

$$
\frac{\partial E}{\partial t}-D \nabla^{2} E+\frac{\omega}{Q} E=0
$$

where $E=E(x, y, z, t ; w)$ is the energy densjty in a unit frequency band about $w$, $D$ is the diffusivity constant, and $Q$ is the quality factor. The point-source solution to (1) is

$$
E(r, t ; \omega)=\frac{W(\omega)}{(4 \pi D t)} 3 / 2 e^{-\frac{r^{2}}{4 D t}} e^{-\frac{\omega t}{Q}}
$$

where $r=\left(x^{2}+y^{2}+z^{2}\right)^{\frac{1}{2}}$ is the source-receiver distance, and $w(\omega)$ is the total energy generated in the unit frequency band around $\omega$. The diffusivity is related to the wave scattering process by analogy with the scattering of particles moving with a certain mean free path, $\mathrm{L}$, as

$$
D \simeq V L \text {. }
$$


Here $\mathrm{V}$ is the velocity of wave propagation and $\mathrm{L}$ is the distance over which the wave energy is reduced to $e^{-1}$ by scattering. The diffusivity is generally a measure of how efficiently the "pool" of scattered energy becomes homogeneous in a macroscopic sense. Several investigators modeling seismicwave energy propagation this way (Aki and Chouet, 1975, and Wesley, 1965), have found that $D \simeq 10^{12} \pm 10 \mathrm{~cm}^{2} / \mathrm{sec}$. For observations at short range such as those represented in a stacked reflection trace, the exponential tern. involving distance is effectively unity. (Note that for a processed trace in a CDP section, $r$, the source-receiver distance, is actually zero.) Hence,

$$
E(0, t ; \omega)=S(\omega) t^{-3 / 2} e^{-\frac{\omega t}{Q}}
$$

where $S(\omega)=W(\omega) /(4 \pi D)^{3 / 2}$ is the source term. Observed amplitudes should then vary as

$$
A(t ; \omega)=s(\omega) t^{-3 / 4} e^{-\frac{\omega t}{2 Q}}
$$

where $A$ and $S$ are square roots of $E$ and $S$.

Taking the logarithm of (5),

$$
\log _{10} A(t ; \omega)=C(f)-\frac{3}{4} \log _{10} t-b t
$$

where $C(f)$ is the source function, $b=\left(\log _{10} \mathrm{e}\right) \pi f / Q$ is the attenuation parameter, and $f=\omega / 2 \pi$. Note that amplitude decaysdue to two separate effects, that of scattering and that of anelastic loss; separation of these effects can be accomplished following the method of Aki and Chouet (1975) in which the source function, $C(f)$, and the attenuation parameter, $b$, are determined by least squares calculations. By analyzing our seismograms over several frequency ranges for each of the three zones across the spread, we can determine values of $Q$ and relative diffusivities in the Bear ValleyBickmore Canyon area of the San Andreas fault.

Preliminary data processing indicates that amplitude decay as a function of time is more extreme in the eastern Franciscan crust than in the granitic crust west of the fault. These preliminary data are in the form of amplitude decay curves, an example of which, for $670 \mathrm{~m}$ offset (source-receiver) distance and a set of source VP locations, is presented in Figure 9. Although the source-receiver distance is not zero, it is still near-field, compared to the total distance traveled by the reflected and otherwise backscattered waves.

We have fit roughly these decay curves to equation (6) to obtain, for $12 \mathrm{~Hz}$, the $Q$ values shown in the figure. The results appear reasonable, and the next step will be to utilize the stacked data in a more systematic search for frequency dependence in the loss mechanisms characteristic of the two crustal types and the fault zone. 


\section{SUMMARY AND CONCLUSIONS}

An extensive Common Depth Point reflection survey was conducted in San Benito County, crossing the San Andreas Rift Zone in the vicinity of Bear Valley. The survey was supplemented by recordings taken with source locations as far as $16 \mathrm{~km}$ to the west and $12 \mathrm{~km}$ to the east of the recording spread of geophones.

Six laterally offset sources provided some data which aided in assessment of the three-dimensional continuity of the structure found. By 1uck, two small earthquakes were recorded and provided valuable velocity information. The second of these, near the Melendy Ranch, was fortunately in such a position that a nodal line (at right angles to the slip direction) intersected the recording spread and provided additional detailed location information.

A strong gradient of average velocity away from the fault zone has been found. The velocity decrease of approximately $30 \%$ over about $10 \mathrm{~km}$ seems clear. Farther to the west, the gradient becomes more gentle and may reverse itself as the line encroaches on the Salinas Valley. Due to the fact that the isolated shotpoints in the Salinas Valley gave rise to unreversed reflection or refraction profiles, it is not possible to separate the effects of dip of the reflectors and velocity change. Apparent dip, however, on the west end of the line (near $\mathrm{L}-1$ ) appears to be to the west.

The quality of the raw reflection records is best near VP 200, the west end of the CDP line, but a subsidiary area of good quality reflections has been found very near to the Rift Zone and a small amount near the east end of the line. These localities will be of considerable use in possible future temporal monitoring of reflection velocities. The stacked records are not as good in some of these areas due to the uncertinaty of NMO corrections on most of the traces used for composite and the deterioration occurs due to interference of incorrectly adjusted raw records.

Elevation corrections were initially applied using a velocity of $8000 \mathrm{ft} / \mathrm{s}$ to correct to a flat datum. Subsequently, the individual records were subjected to the proprietary program AUTOSTATICS which did, in fact, within the allowance imposed of $50 \mathrm{~ms}$, make additional shifts which allowed a best fit of surface consistent corrections with the raw reflection data.

Crooked line processing of the data involves correction for the straight line distances between relevant sources and receivers before NMO correction and, later, the ability to plot in three dimensions the raw data reflecting points. This is only a first approximation, since such a plot is based on the assumption of flat reflecting planes. Later it is possible to select bands of data for playout and also make estimates of the amount and direction of crossdip. This survey, using the proprietary SLALOM processing, showed appreciable cross-dip to the north. On the western end of the line this amounts to about $90 \mathrm{~m}$ in a distance of $244 \mathrm{~m}$ or an angle of $20^{\circ}$. This may, in fact, be the predominant real dip, since much of the apparent east dip shown on this western part of the CDP section is due to decrease in average velocity to the M-discontinuity toward the Rift Zone. The velocity effect is not present when 
comparing two cross-sections for two different SLALOM bands. The "Scattergram" therefore gives an incorrect relation between the VP's and the reflecting point, since the latter must be migrated to the south as a consequence of the north dip.

On the eastern side of the San Andreas Rift Zone, there is seen to be no cross component of dip measurable. There were, however, no determinations possible at Moho depth.

Along the entire CDP line, reflections shallower than 3.0 seconds travel time can often be picked with confidence. These reflections are so good in certain locations that abrupt change of quality may be due to faulting. There is also reasonable evidence of a lack of reflections generally in the 4.0 to 6.0 second travel-time zone, thus implying a travel medium in which the velocity changes only slowly. This is consistent with the low velocity zone previously suggested as being present and may explain, because of the presumption of low strength, the non-occurrence of earthquakes below about $10 \mathrm{~km}$. This is the zone where all stress adjustments are made easily and continuously, without seismic wave emissions accompanying fractures.

Below the 6.0 second trave1-time depth, there is no evidence of disconformities in reflections, although their quality is poor. The reflections associated with the M-discontinuity seem, in fact, to occur through a transition zone $10 \mathrm{~km}$ or more thick, although part of this apparent thickness is probably due to persistence of multiple reflections. To give reflections in the $6-24 \mathrm{~Hz}$ band, sudden changes in acoustic impedance must occur for zones no thicker than $100-500 \mathrm{~m}$.

In the final analysis, the data must be migrated to correct subsurface positions before spatial sorting and stacking. This operation is extremely expensive computationally, and requires, of course, a correct velocity model. As a first step in such a process, we have attempted to construct a 2-dimensional velocity model by a simple procedure of matching M-discontinuity reflections and first arrivals by ray-tracing, under the assumption that the Moho is flat. The resulting model appears to be a reasonable one in light of the body of data on velocities near the San Andreas fault zone.

The fault zone proper is characterized by a very low velocity and a large number of diffraction sources. As well as can be determined, viewing through an extremely distorting velocity field, the fault zone as characterized by diffraction is a vertical feature.

Attenuation properties vary considerably across the reflection profile, with apparently high Q crust characterizing the western crustal block and much greater loss apparent in the fault zone and in the eastern crustal unit. Estimates of $Q$ from a diffusion model yield values of $50-100$ at the low end and 200-300 at the upper range.

By and large, the experiment was a success. The fault zone can be imaged to Moho depth with useful resolution, if the 3-dimensionality of the structure is considered. The field procedures are demanding and heavy signal enhancement 
is required. Simultaneous determination of structure and velocity models is difficult due to severe interaction. It is possible that fault zone imaging in a monitoring mode may offer a powerful technique in the search for perturbations due to stress changes in the earthquake nucleation process. 


\section{REFERENCES}

Aki, K. and B. Chonet (1975). Origin of coda waves: source, attenuation, and scattering effects, J. Geophys. Res., 80, 3322-3342.

Aki, K. and W.H.K. Lee (1976). Determination of three-dimensional velocity anomalies under a seismic array using first $P$ arrival times from local earthquakes 1. a homogeneous model, J. Geophys. Res., 81, 4381-4399.

Boore, D.M. and D.P. Hill (1973). Wave propagation characteristics in the vicinity of the San Andreas fault, Proc. Conf. Tectonic Prob1. San Andreas Fault System, Stanford Univ. Pub1. Geol. Sci., 13, 215-224.

Engdah1, E.R. and W.H.K. Lee (1976). Relocation of local earthquakes by seismic ray tracing, J. Geophys. Res., 81, 4400-4406.

Healy, J.H. and L.G. Peake (1975). Seismic velocity structure along a section of the San Andreas Fault near Bear Valley, Calif., Bull. Seism. Soc. Am., $\underline{65}, 1177-1197$.

McEvilly, T.V. (1966). Crustal structure estimation within a large scale array, Geophys. J., 11, 13-17.

McEvilly, T.V. and R. Clymer (1975). Reflection Seismic Survey near the San Andreas Fault, Final Report to U.S.G.S. on Contract 非14-08-0001-14845.

Muir, F. and J.P. Morrison (1973). Anti-Aliasing of Spatial Frequencies by Geophone and Source Placement, U.S. Patent 3,719,924.

Steppe, J.A. and R.S. Crosson (1978). P-Velocity models of the Southern Diablo Range, California, from inversion of earthquake and explosion arrival times, Bu11. Seism. Soc. Am., 68, 357-367.

Stewart, S.W. (1968). Preliminary comparison of seismic trave1 times and inferred crustal structure adjacent to the San Andreas Fault in the Diablo and Gabilan ranges of central California, Proc. Conf. Geol. Probl. San Andreas Fault System, Stanford University, Pub1. Geo1. Sci., 11, 218-230

Waters, K.H. (1978). Reflection Seismology - A Tool for Energy Resource Exploration, John Wiley \& Sons, New York.

Wesley, J.P. (1965). Diffusion of seismic energy in the near range, J. Geophys. Res., 70, 5099-5106. 
Figure 1. Index map showing CDP 1ine (segments A, C, C form L-0 to N-9) and long offset VPs (LI-4, L7-10).

Figure 2. Equi-velocity contoured crustal section across the San Andreas fault zone at Bickmore Canyon. Fault trace is at $X=22.5 \mathrm{~km}$. Crustal thickness is $23.5 \mathrm{~km}$.

Figure 3. Ray paths for Moho P-wave reflections for four source-receiver pairs. Note the distortion to eastward apparent velocity on C-C' which appears on reflection sections as strong apparent Moho dip. Section parameters as in Figure 2.

Figure 4. Ray paths at $3^{\circ}$ spacing in take-off angle for direct $\mathrm{P}$-waves from earthquake source at $6 \mathrm{~km}$ depth on the San Andreas fault. Note the strong focusing in the fault zone. Section parameters as in Figure 2 .

Figure 5. Final stacked section showing calculated Moho reflection times using model of Figure 2 .

Figure 6. Raw data for western offsets $\mathrm{L}-0$ to $\mathrm{L}-4$ into spread A with superimposed calculated arrival times for first arrivals and Moho reflections using model of Figure 2.

Figure 7. Raw data for eastern offsets L-7 to L-10 into spread A with superimposed calculated arrival times for first arrivals and Moho reflections using model of Figure 2. Shot point L-8 is not ca1culated because it is too much off-line.

Figure 8. Preserved amplitude stacked section with calculated Moho reflection times. Note the striking differences in reflected energy among locations east of, west of, or within the fault zone.

Figure 9. Logarithmic amplitude decay curves for $670 \mathrm{~m}$ offset at severa1 VP positions, along with curves of equation (6) for various assumed $Q$ values. Numbers on decay curves are approximate $Q$ values from rough curve fitting, indicating generally greater loss in the eastern crustal block. 


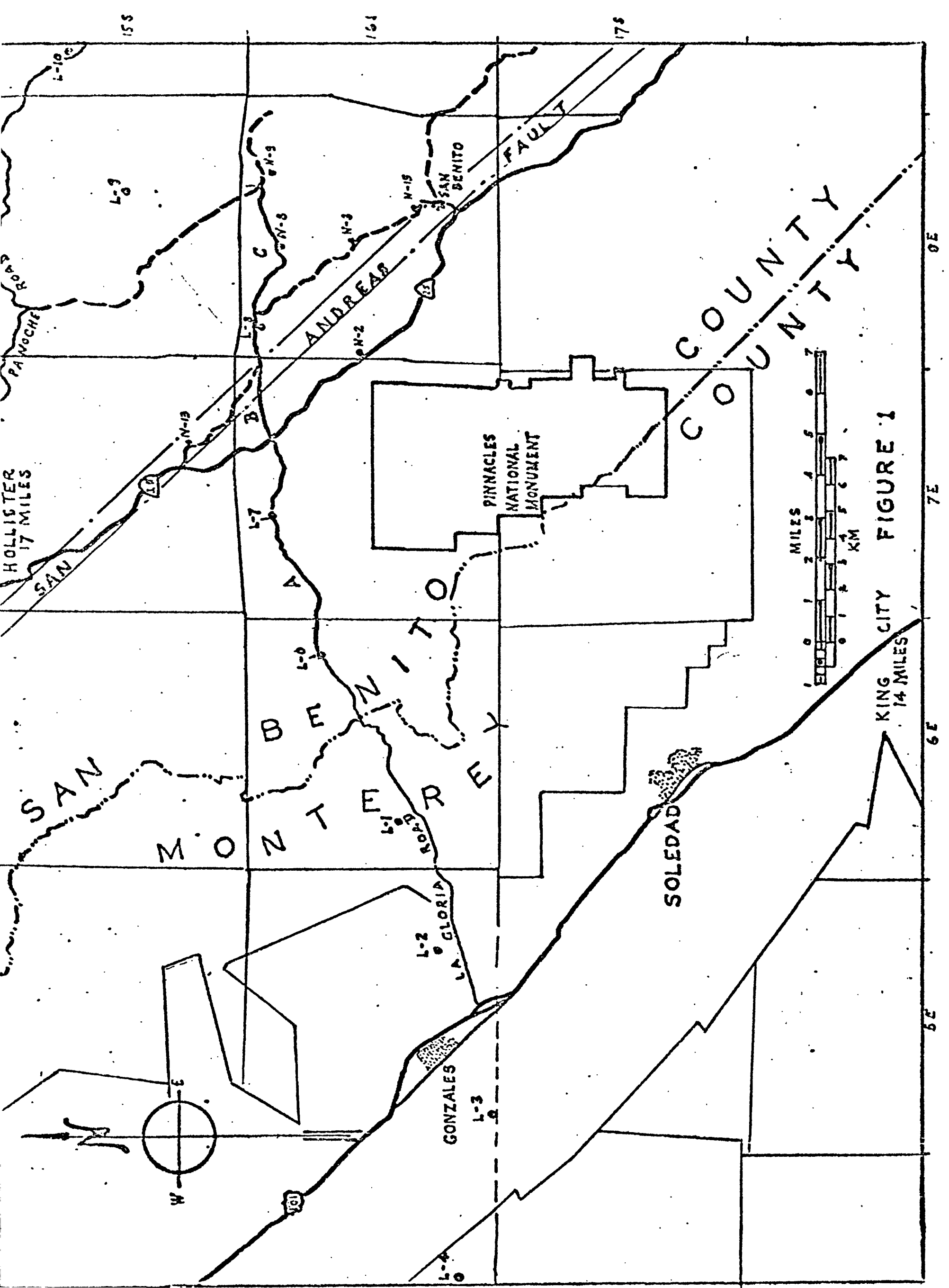




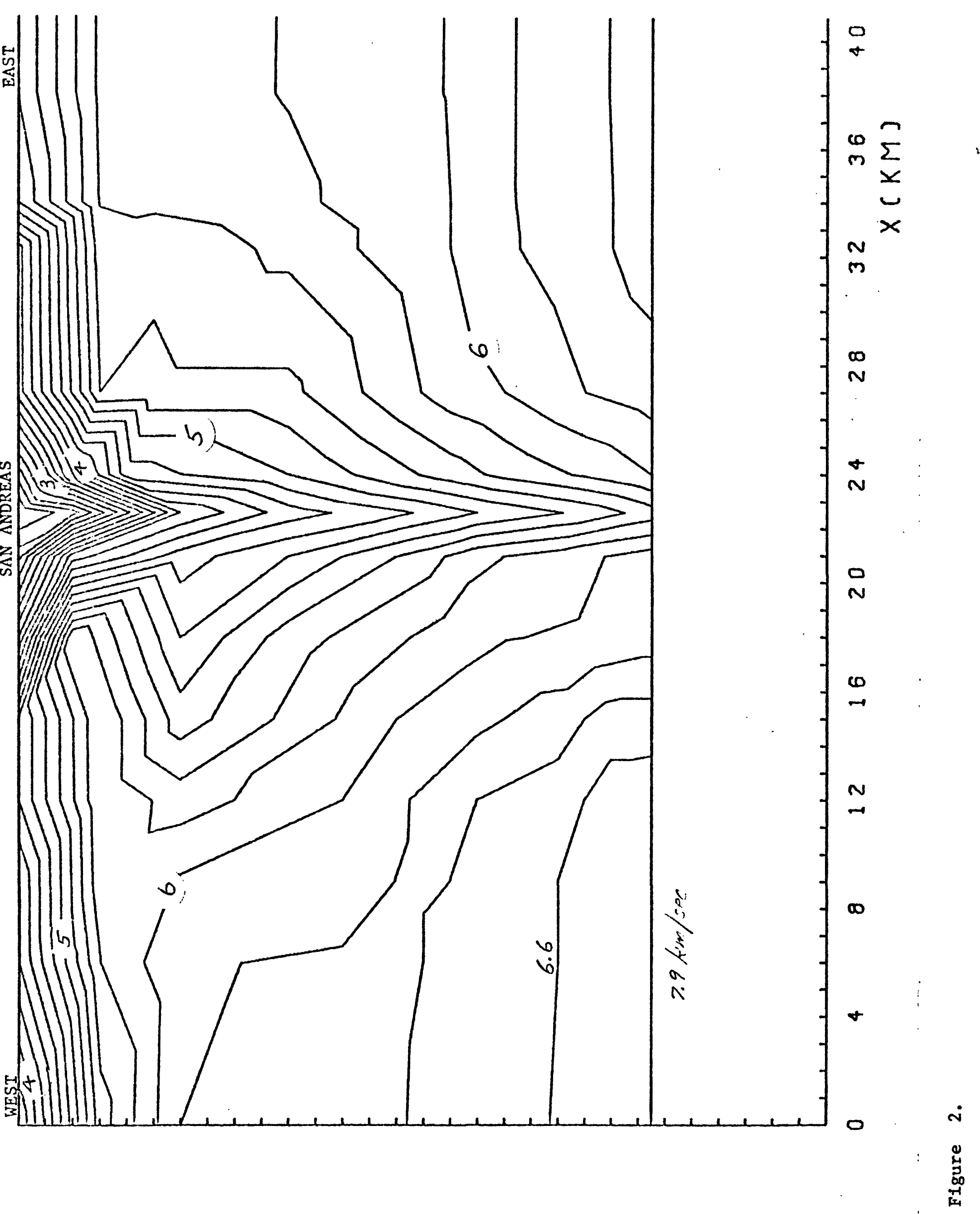

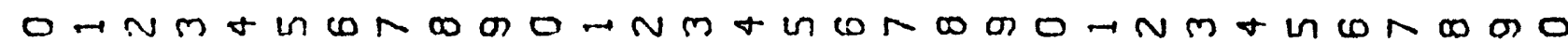

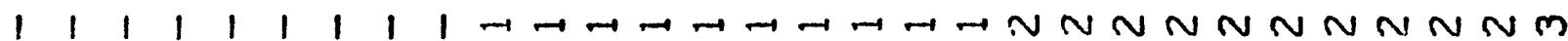
$[W \times] Z$ 


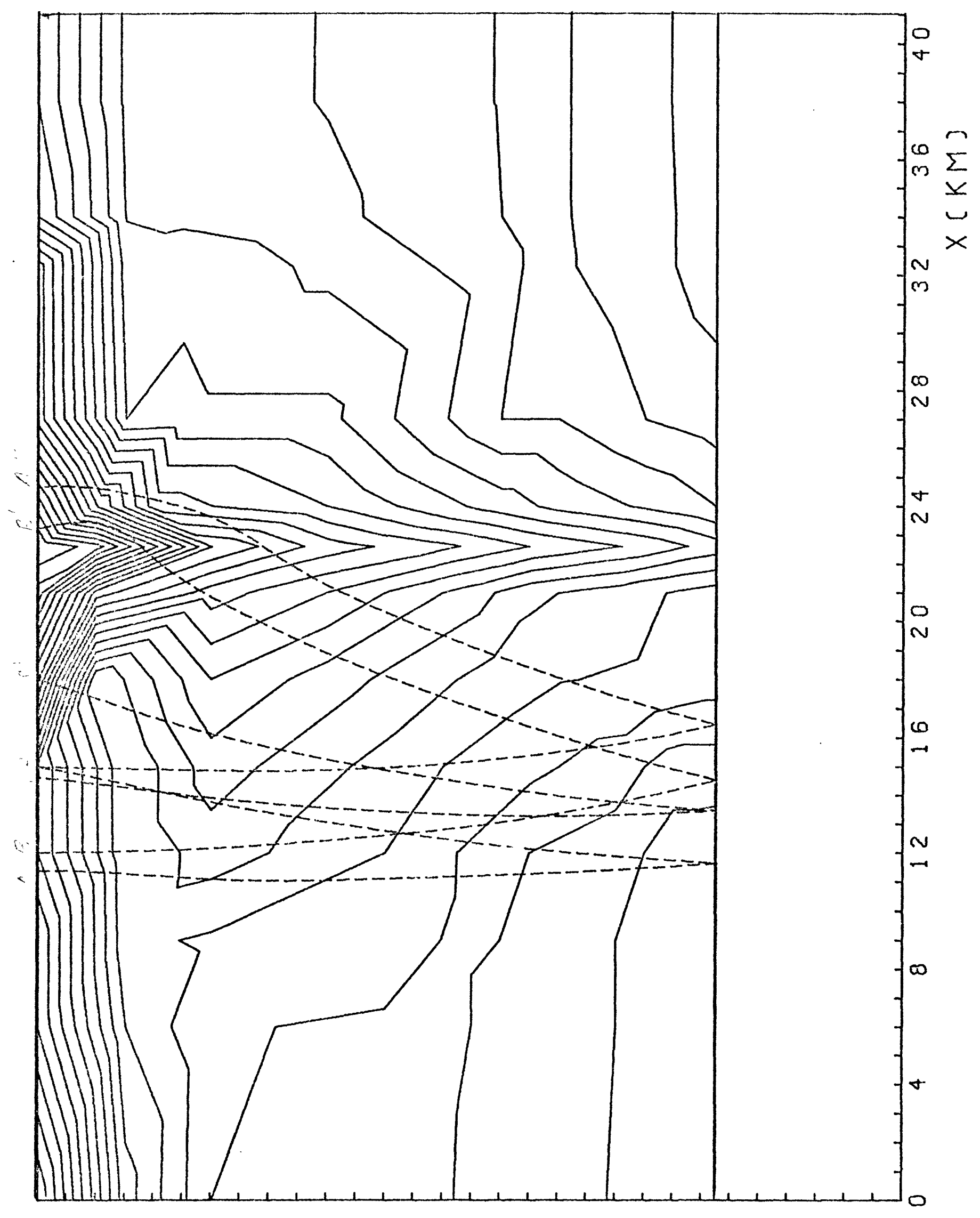

\begin{tabular}{l}
$\dot{m}$ \\
0 \\
\multirow{2}{0}{} \\
$\dot{0}$ \\
$\dot{01}$
\end{tabular}

$0 \rightarrow N m+\ln \omega N$ m

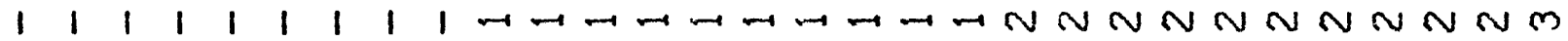
$(W \times) Z$ 


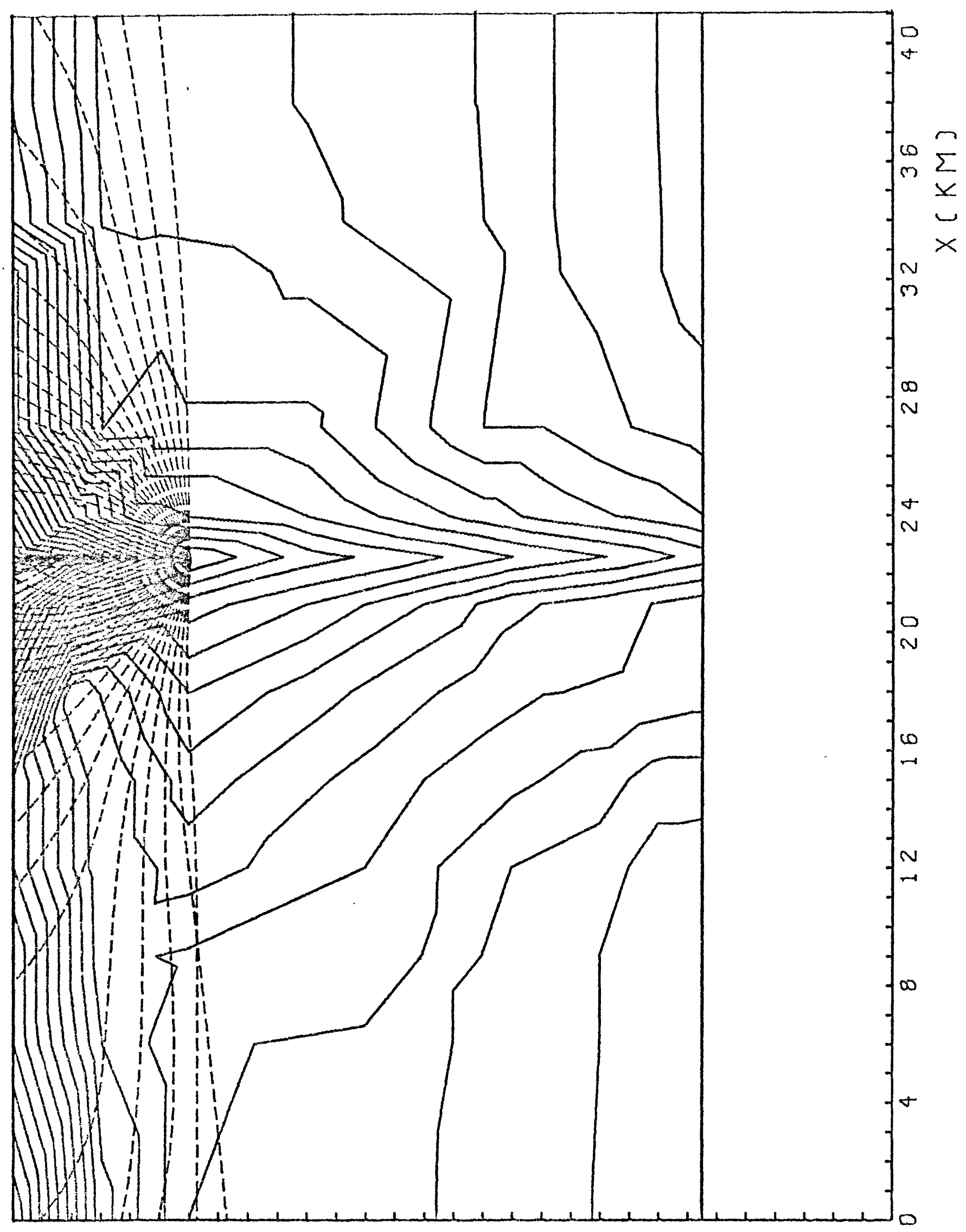

OTNM+UயN 

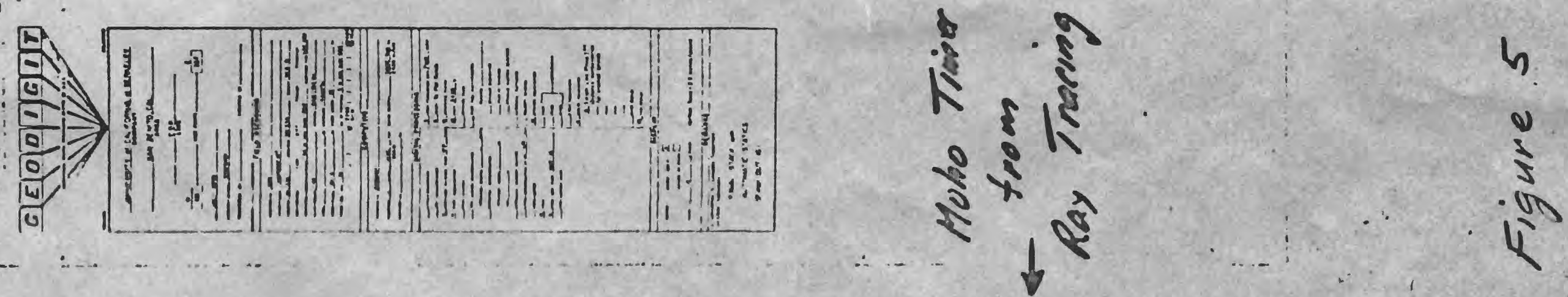

1أ

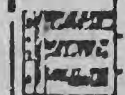

8)

S-

(1) (2)

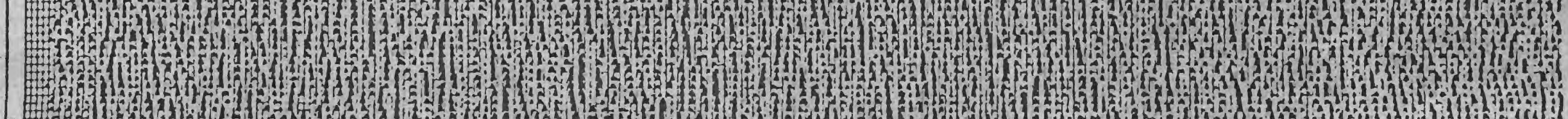
A

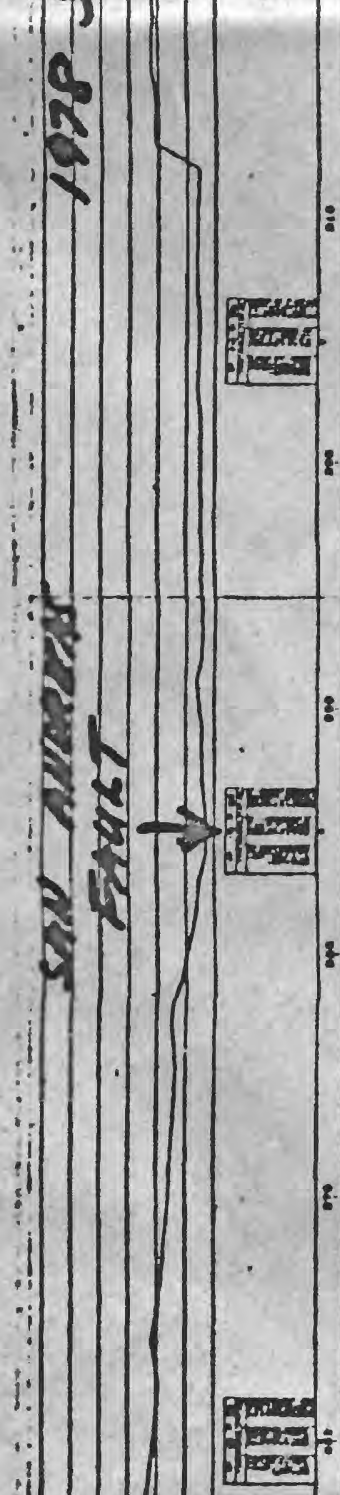

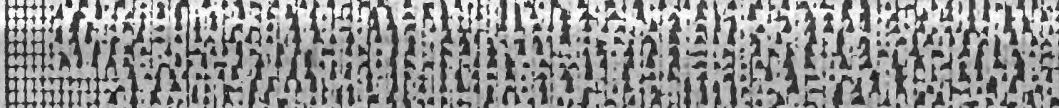

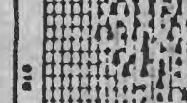



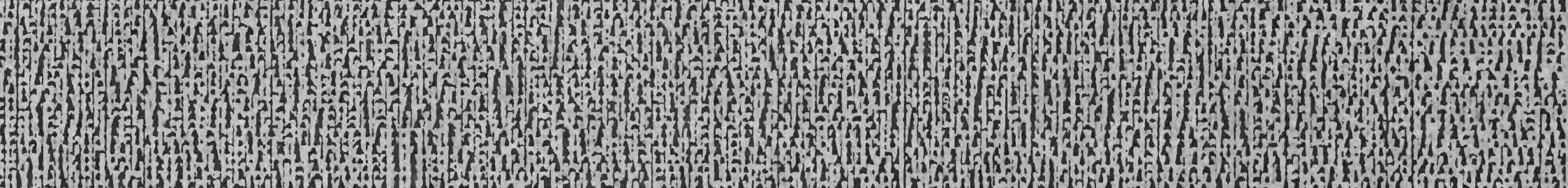

:

,

= (1) 
太

\section{0}

t. (1)

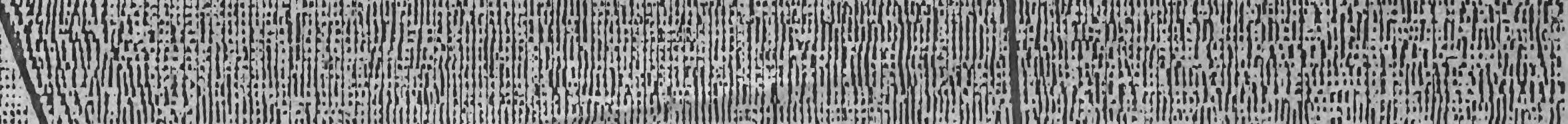

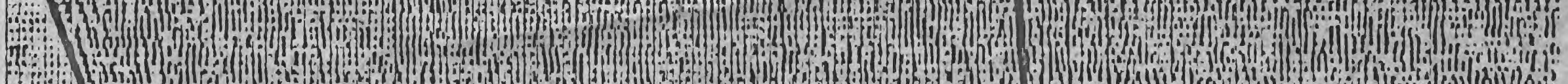

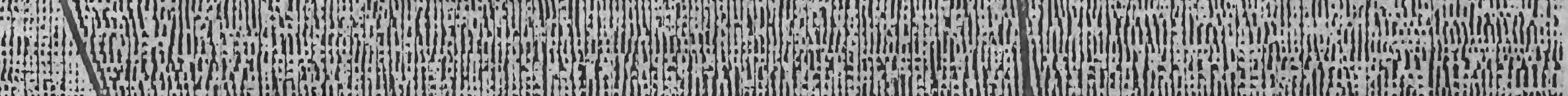

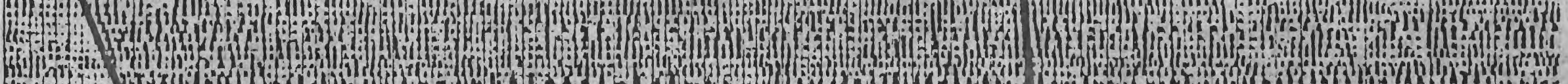

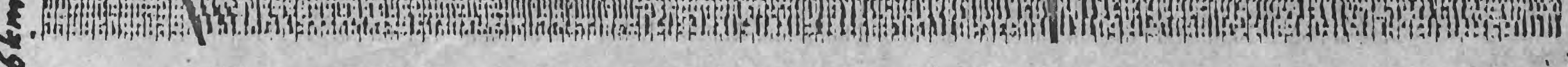
-

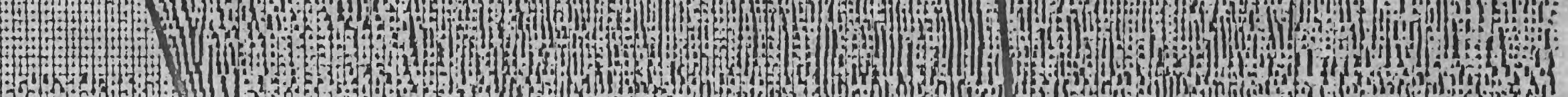
H.7. 2 (n)

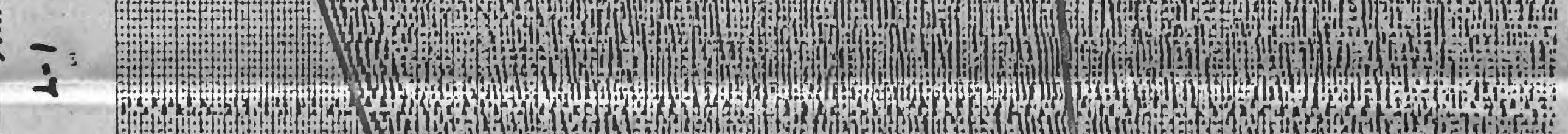
. ₹.mo

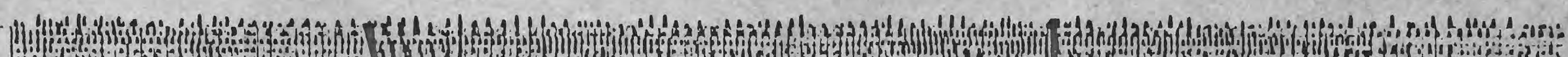

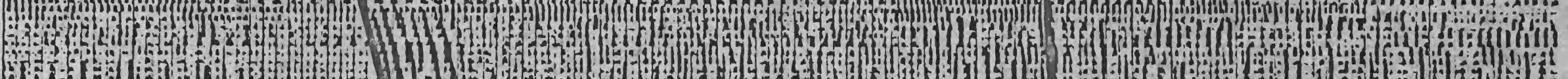

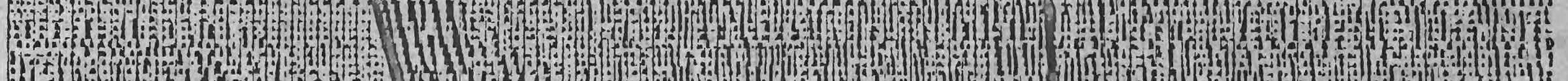
s

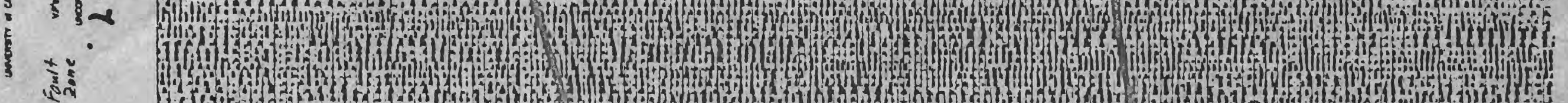

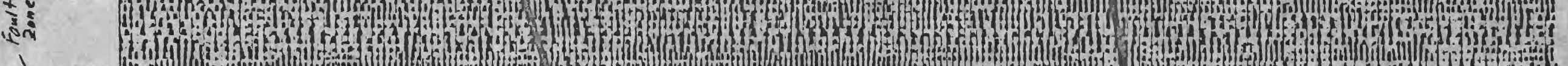

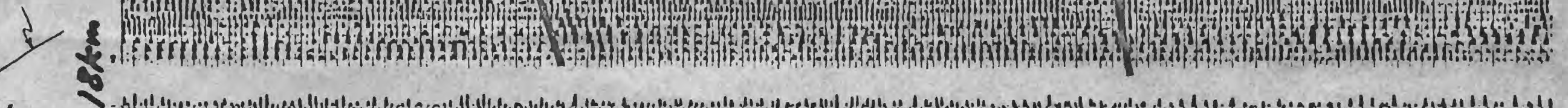

- - - -

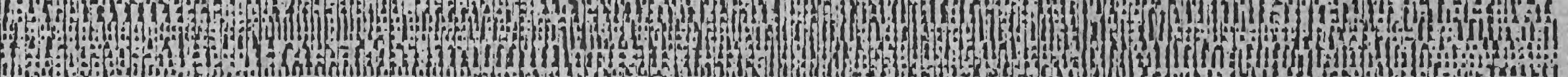

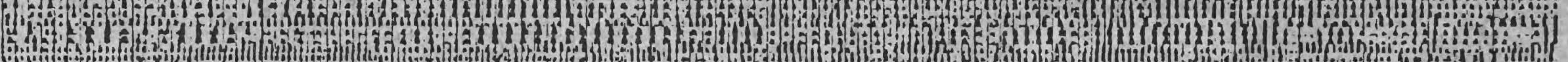

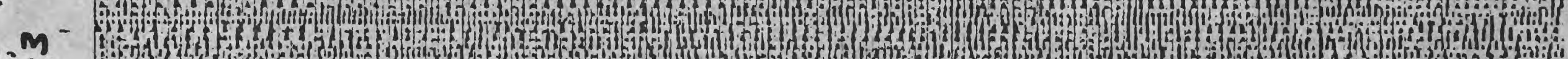

$\because \neg$ -

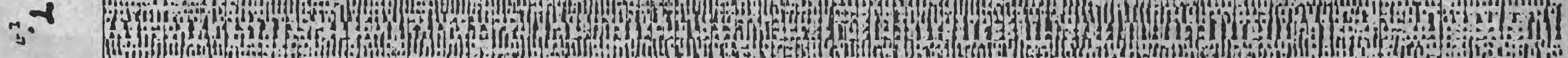

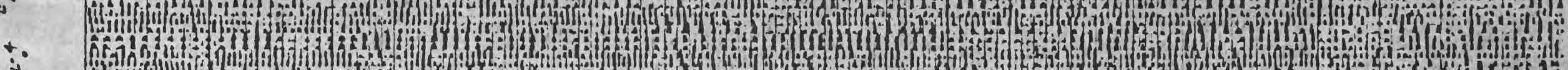
161 by

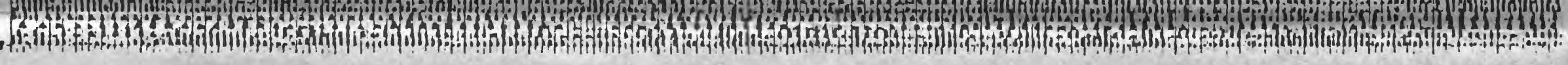

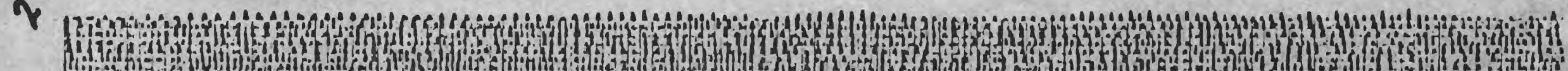

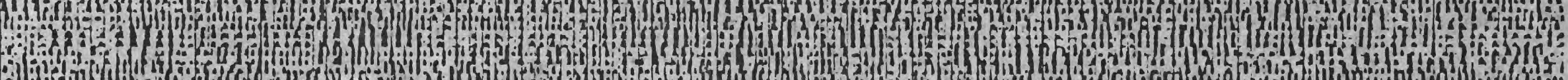
3.1.1.

+ rom -

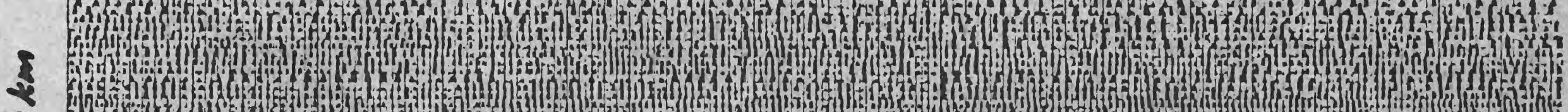
o

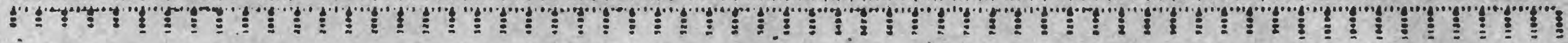



Wey
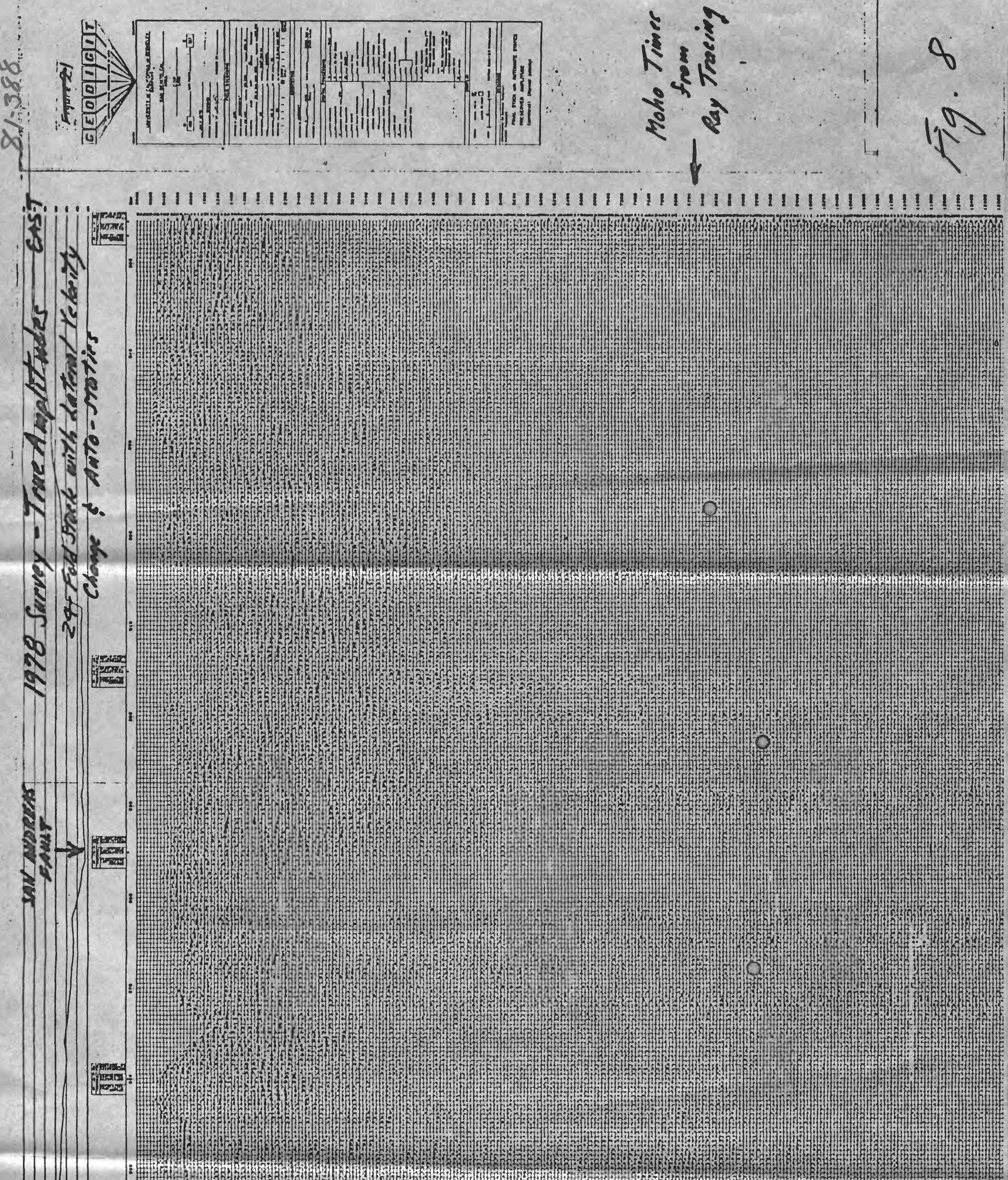


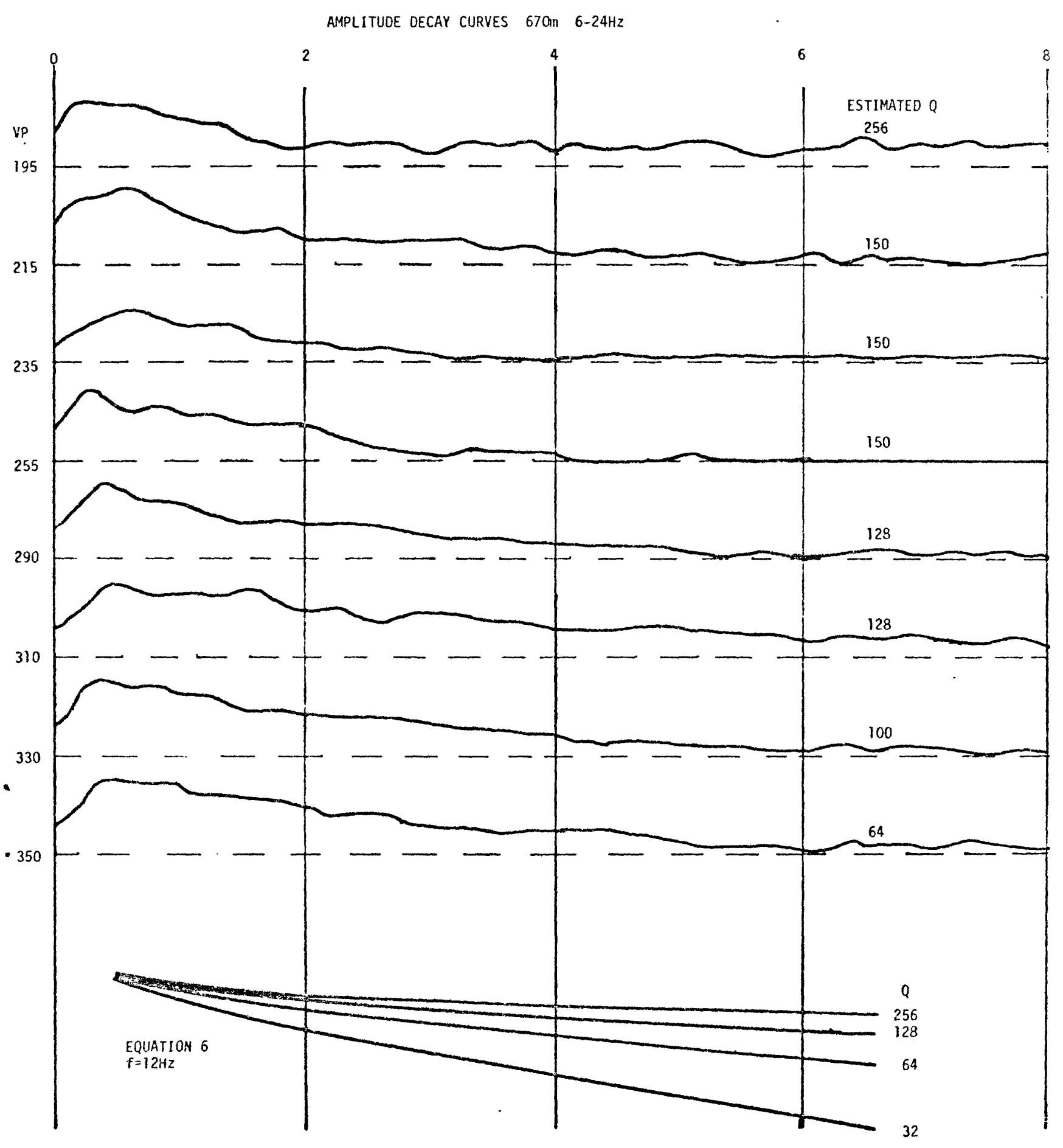

Figure 9. 